\title{
The real-world cost-effectiveness of bariatric surgery for the treatment of severe obesity: a cost-utility analysis
}

\author{
Erica L.W. Lester MD MSc, Raj S. Padwal MD MSc, Daniel W. Birch MD MSc, Arya M. Sharma MD DSc, \\ Helen So PhD, Feng Ye MSc, Scott W. Klarenbach MD MSc
}

Abstract

Background: Severe obesity is associated with adverse health outcomes and increased risk of death. This study evaluates the realworld cost-utility of therapy for severe obesity, from the publicly funded health care system and societal perspectives.

Methods: We conducted a cost-utility analysis using primary data from a prospective observational cohort of adults living with severe obesity (BMI $\geq 35 \mathrm{~kg} / \mathrm{m}^{2}$ and a major medical comorbidity or BMI $\geq 40 \mathrm{~kg} / \mathrm{m}^{2}$ ) who were enrolled in a regional obesity program over 2 years. We extrapolated 10-year and lifetime Markov models, validated and supplemented with literature sources, to compare medical, surgical and standard care therapies. We performed deterministic and probabilistic sensitivity analyses.

Results: The cohort included 500 adults living with severe obesity, 150 of whom received laparoscopic surgical therapy. From a publicly funded health system perspective, at 2 years, surgical therapy had an incremental cost-effectiveness ratio (ICER) of \$54 456 per quality-adjusted life-year (QALY) compared with standard care therapy. Over a lifetime, it had an ICER of \$14 056 per QALY. From the societal perspective, at 2 years, surgical therapy had an ICER of \$340 per QALY; over a lifetime, it was the dominant option. The results were robust to sensitivity analysis.

Interpretation: From a public health care perspective, surgery for severe obesity is cost effective, and when approached from a societal perspective, it becomes cost saving. Real-world data support using surgical therapy for severe obesity, and our results contribute to the health economic and clinical literature with regard to a robust analysis from a societal perspective.

evere obesity, defined as a body mass index (BMI) greater than $35 \mathrm{~kg} / \mathrm{m}^{2}$, is associated with adverse health outcomes, ${ }^{1-4}$ increased health care resource use and reduced home and workforce productivity. Numerous approaches to treat obesity have been developed, including lifestyle modifications, pharmacotherapies and surgical interventions. ${ }^{5-10}$ Bariatric surgery has emerged as one of the most clinically effective options, with numerous studies demonstrating its effectiveness. ${ }^{3,11}$

Although many studies have examined cost-effectiveness from the health payer perspective, a broader perspective that fully captures all the costs and consequences of obesity and its treatment is lacking. ${ }^{3,12}$ Failing to consider the societal perspective can underestimate opportunity costs and misdirect resource allocation; this is especially relevant when assessing interventions that increase productivity among the workingage population and their quality of life. Further, most analyses use estimates from multiple sources, which may not reflect pragmatic, real-world resource use and outcomes. Failure to incorporate factors such as compliance or outcomes of treatment programs, outside of a rigorous study protocol, may lead to biased estimates of the cost-effectiveness of bariatric treatment programs.
Using prospective, empirical data from a regional bariatric program, we conducted an economic evaluation of surgical and medical therapy compared with standard care from both the public health care system and societal perspectives over 2 years, and extrapolated to 10 -year and lifetime time horizons.

\section{Methods}

\section{Study design}

We used rigorously collected data from a pragmatic clinical treatment program study, the Alberta Population-based

Competing interests: Erica Lester reports support from the Alberta Innovates Health Solutions Clinician Fellowship. Daniel Birch is a founding member of the Canadian Association of Bariatric Physicians and Surgeons. Arya Sharma is a past president of the same association. Scott Klarenbach is supported by the Kidney Health Research Chair. No other competing interests were declared.

This article has been peer reviewed.

Correspondence to: Erica Lester, elester@ualberta.ca

CMAJ Open 2021. DOI:10.9778/cmajo.20200188 
Prospective Evaluation of the Quality of Life Outcomes and Economic Impact of Bariatric Surgery (APPLES) to inform this cost-utility analysis. A detailed study protocol and results of the APPLES study, which was conducted from 2008 until 2010, have been published (Appendix 1, available at www.cmajopen.ca/content/9/2/E673/suppl/DC1). ${ }^{1,5,13-17}$

In the APPLES study, data were captured prospectively at $6,12,18$ and 24 months after enrolment, including demographics, anthropometrics, health-related quality of life, medication use, and detailed health care resource use (through linkage with administrative data). Patient surveys also captured costs, including transportation needs, out-ofpocket health-related purchases, attendance at work and enrolment in government support programs. ${ }^{1,5} \mathrm{We}$ used outcomes from the 24-month data collection in our modelling study.

\section{Cohort}

We conducted our analysis using data from the participant cohort in the APPLES study. ${ }^{1}$ This study included adult patients (18-60 yr) enrolled in a regional obesity program, with BMI levels $\geq 35 \mathrm{~kg} / \mathrm{m}^{2}$ and a major medical comorbidity or with BMI levels $\geq 40 \mathrm{~kg} / \mathrm{m}^{2}$. Patients were assigned to 1 of 3 groups: medical therapy, surgical therapy or standard care (Table 1). ${ }^{1}$ The study sample size of 500 adult patients living with severe obesity was determined a priori. The standard care group served as a control group and consisted of patients who were on the program's waitlist, with no direct weight loss therapy administered. Of the 150 patients who had surgery, 48 had an adjustable gastric band, 51 had a sleeve gastrectomy and 51 had a Roux-en-Y gastric bypass. All surgeries were conducted laparoscopically. ${ }^{1}$ All patients were deemed surgical candidates, as per the criteria used in Alberta. ${ }^{18}$

\section{Model structure}

We assessed outcomes at 2 years by treatment group using primary data from the APPLES study. We created Markov models using 10-year and lifetime time horizons, applying a half cycle correction. We allocated patients to the health states of death, diabetes, hypertension, diabetes and hypertension or no obesity-related comorbidity, as per the results of the 2-year cohort study; patients could transition between states during each 1-year cycle (Figure 1). We applied baseline characteristics for each treatment arm at the completion of the APPLES study, as well as initial cost and quality-adjusted life-years (QALYs), to the respective health states to account for the changes that occurred during the study.

We obtained transition probabilities between health states from primary data; when unavailable from primary data, we used probabilities informed by focused literature review (Appendix 2, available at www.cmajopen.ca/content/9/2/ E673/suppl/DC1). The approach to determining probabilities is outlined in Appendix 1. We assessed costs and effects at a discount rate of $5 \%$, as per convention. ${ }^{19}$

\section{Model parameters}

For the 2-year assessment, we used utility values from the APPLES cohort, measured using the EQ-5D-3L survey and derived via the US valuation system. ${ }^{20}$ For the 10 -year and lifetime models, we extrapolated utility measurements by performing multivariable analysis on the APPLES data (using the mean BMI for each health state) and using the resultant regression equation to calculate the utility associated with each health state by age. We validated our calculated values by comparing them to those collected by the Health Quality Council of Alberta; the values from the APPLES data were minimally and consistently lower than those from the Health Quality Concil. Although the data from the Health Quality Council did not differentiate comorbidities, this finding increased our confidence in the extrapolation.

We defined the health care system and societal perspectives as per the Canadian Agency for Drugs and Technologies in Health guideline (details concerning cost determinations are in Appendix 1). ${ }^{19}$ The former includes costs to the publicly funded health care system, patients and their families.

The societal perspective includes the components of the health care system perspective, combined with the direct costs

\begin{tabular}{|c|c|c|c|c|}
\hline \multirow[b]{2}{*}{ Characteristic } & \multicolumn{4}{|c|}{ No. $(\%)$ of patients* } \\
\hline & $\begin{array}{l}\text { Standard } \\
\text { care } \\
n=150\end{array}$ & $\begin{array}{l}\text { Medical } \\
\text { therapy } \\
n=200\end{array}$ & $\begin{array}{l}\text { Surgical } \\
\text { therapy } \\
n=150\end{array}$ & $\begin{array}{c}\text { All patients } \\
n=500\end{array}$ \\
\hline Age, yr, mean \pm SD & $45.6 \pm 9.2$ & $46.0 \pm 10.0$ & $45.3 \pm 9.5$ & $45.7 \pm 9.6$ \\
\hline $\mathrm{BMI}, \mathrm{kg} / \mathrm{m}^{2}$, mean $\pm \mathrm{SD}$ & $48.8 \pm 8.0$ & $46.5 \pm 8.2$ & $36.4 \pm 7.6$ & $44.8 \pm 9.0$ \\
\hline Sex, female & $136(90.7)$ & $174(87.0)$ & $131(87.3)$ & $441(88.2)$ \\
\hline Hypertension & $96(64.0)$ & $118(59.0)$ & $66(44.0)$ & $280(56.0)$ \\
\hline Diabetes & $71(47.3)$ & $82(41.0)$ & $33(22.0)$ & $187(37.4)$ \\
\hline
\end{tabular}




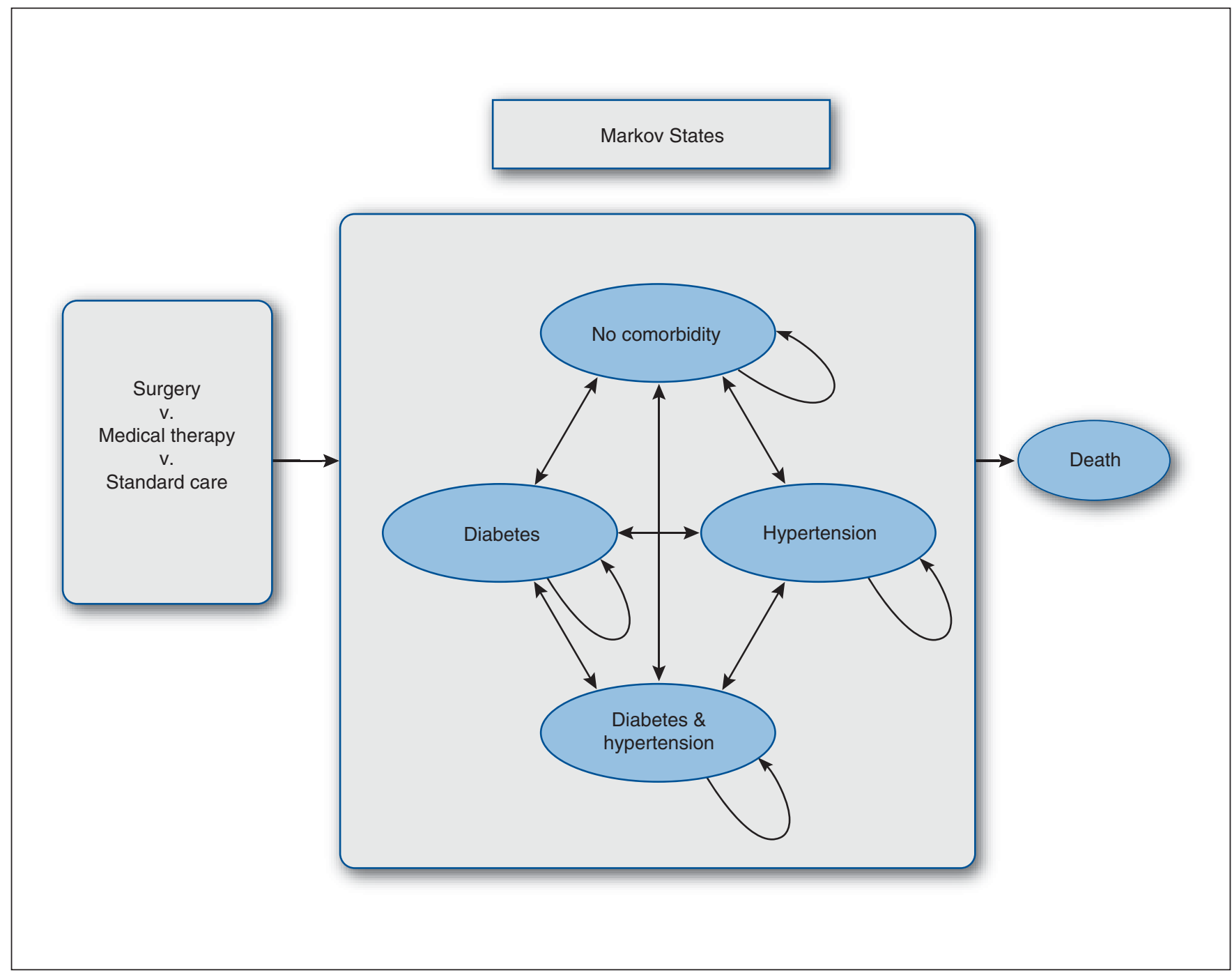

Figure 1: Markov model (10-year and lifetime time horizons) of health states of patients undergoing treatment for severe obesity.

to other publicly funded services and productivity costs. ${ }^{19} \mathrm{We}$ operationalized this definition by adding the cost of the health care system perspective, the costs of income transfer payments (i.e., income for disabled persons, disability and employment insurance benefits), as well as the cost of productivity loss, as measured by the friction method. ${ }^{21}$

Beyond 2 years, we extrapolated the cost of each health state using APPLES data, assuming costs observed for a health state in the second year would persist. Assumptions associated with the cost extrapolation are outlined in Appendix 2. All costs are expressed in 2016 Canadian dollars. We employed the health-specific Consumer Price Index to adjust costs related to health care, as required. ${ }^{22} \mathrm{We}$ adjusted other costs using the Bank of Canada Inflation Calculator. ${ }^{23}$

\section{Statistical analysis}

We report QALYs and the incremental cost-effectiveness ratio (ICER) for each treatment group, compared to standard care. For probabilistic sensitivity analyses, we used Monte Carlo simulation with 10000 iterations. We applied discount rates of 3\% and $0 \%$ in sensitivity analysis. We conducted all modelling using Treeage Pro (2018), and all statistical analysis using Stata 13 . We assessed face, internal and external validity. ${ }^{24} \mathrm{We}$ report the willingness-to-pay value at which an intervention (medical or surgical) became cost effective for each perspective and time horizon.

In the 2-year model, we conducted a probabilistic sensitivity analysis using patient-level costs and its distributions. Transition probabilities were samples from $\beta$ distributions.

In the 10 -year and lifetime model, we assessed all variables via 1 -way sensitivity analysis, comparing surgical or medical therapy to the reference group (standard care) using the ranges in Appendices 1, 2 and 3, available at www.cmajopen. $\mathrm{ca} /$ content/9/2/E673/suppl/DC1. We also conducted probabilistic sensitivity analysis.

\section{Ethics approval}

The initial APPLES study and this cost-utility analysis were approved by the University of Alberta Health Research Ethics Board (Pro00003594 and Pro00060692). 


\section{A Public health care perspective}
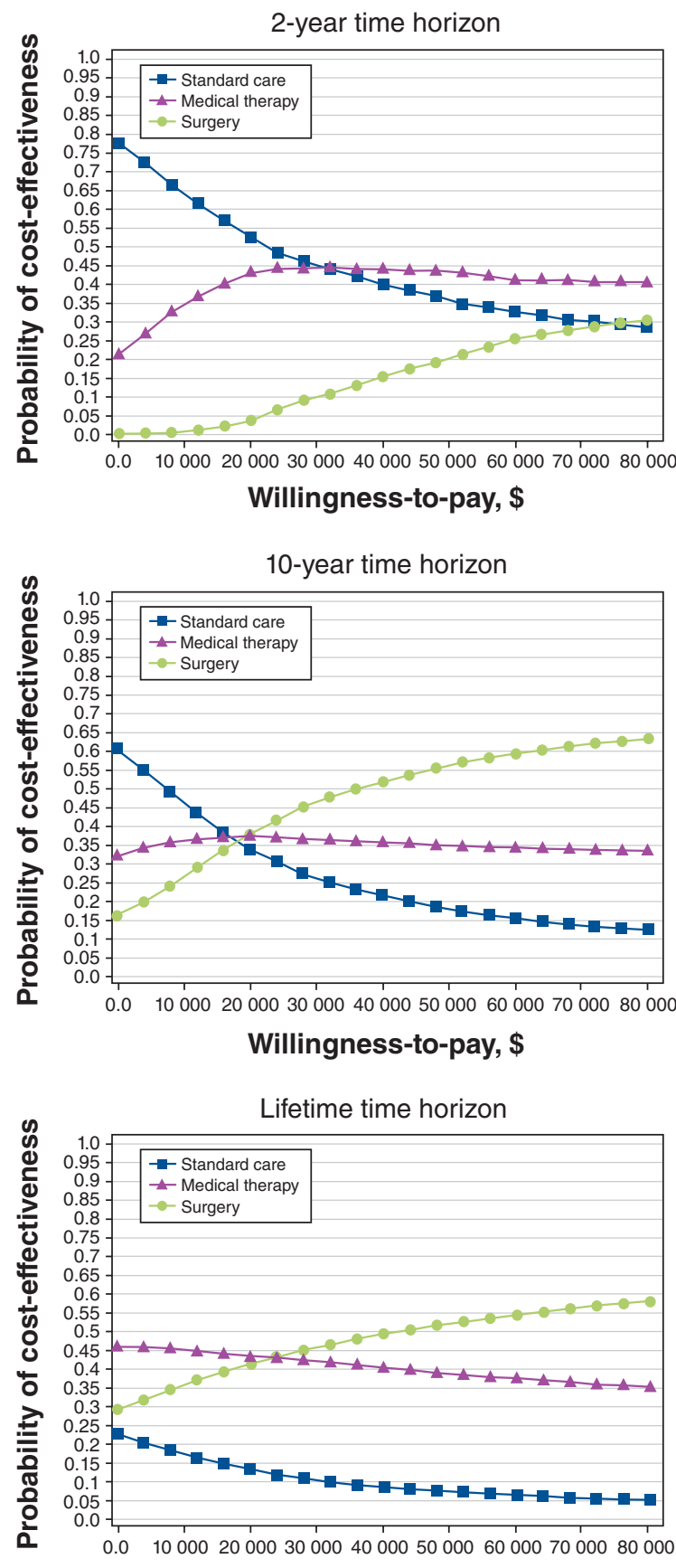

Willingness-to-pay, \$

\section{B Societal perspective}
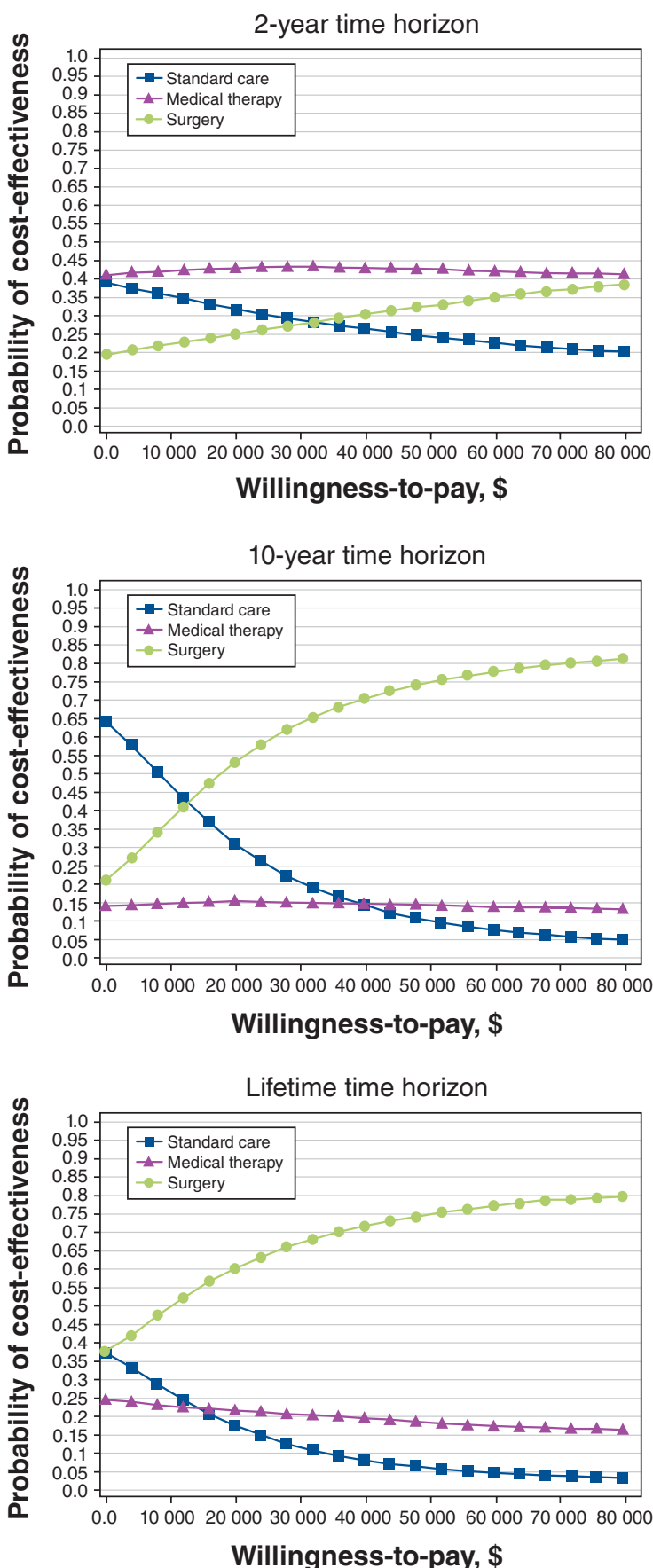

Figure 2: Cost-effectiveness acceptability curves for the 2-year, 10-year and lifetime time horizons from the (A) publicly funded health care system and $(B)$ societal perspectives. The probability of cost effectiveness represents the proportion of simulations that resulted in an incremental cost effectiveness ratio less than a given willingness-to-pay ratio.

\section{Results}

The annual costs and utility estimates by health state for the 500 patients in the APPLES study are reported in Append- ices 3 and 4, available at www.cmajopen.ca/content/9/2/ E673/suppl/DC1, respectively. At 2 years, the absolute QALYs were 1.37, 1.56 and 1.69 for standard care, medical and surgical therapy, respectively (Appendix 5, available at 
www.cmajopen.ca/content/9/2/E673/suppl/DC1). From the health care system perspective, the mean cost of therapy over 2 years for standard care, medical and surgical therapy was \$8040, \$10 590 and \$25 460, respectively. When compared with standard care therapy, surgical therapy demonstrated an ICER of \$54 440 per QALY. The cost-effectiveness acceptability curve is reported in Figure 2, and indicates that medical therapy is favoured at a willingness-to-pay value of $\geq \$ 30000$. From the societal perspective, mean costs were $\$ 51020, \$ 39360$ and \$51 130 for standard care, medical and surgical therapy, respectively (Appendix 5). Surgical therapy had an ICER of \$344 per QALY. Compared with standard care, medical therapy led to more QALYs with lower costs. The cost-effectiveness acceptability curve indicates that medical therapy is favoured at a willingness-to-pay value of $\geq \$ 0$ (Figure 2).

Results of the 10-year time horizon model are reported in Appendix 5. From a health care system perspective, standard care was the lowest cost option. Compared with standard care, medical therapy had an ICER of \$27 280 per QALY and surgical therapy had an ICER of $\$ 19990$ per QALY. The results of the 10-year model from the health care system perspective were robust to most parameter changes in 1-way sensitivity analysis. The 15 variables inducing the greatest change in 1 -way sensitivity analysis are displayed via tornado diagrams in Appendix 6, available at www.cmajopen.ca/content/9/2/ E673/suppl/DC1. Comparing surgery with standard care, the model is sensitive to the cost of the health states of diabetes and hypertension in patients receiving standard care. The model is also sensitive to the mean initial QALY level of surgical patients, obtained directly from the APPLES data. Comparing medical therapy with standard care, the model is most sensitive to changes in the cost of patients with both diabetes and hypertension who received standard care. The probabilistic sensitivity analysis of the 10 -year model indicated that surgical therapy is favoured at willingness-to-pay thresholds above $\$ 19000$ (Figure 2).

When a societal perspective was used in the 10-year model, medical therapy was the lowest cost option (Appendix 5). Standard care had higher costs and worse health outcomes than surgery and medical therapy. The 10-year model from the societal perspective was robust to most parameter changes in 1-way sensitivity analysis (Appendix 6). A similar relationship was seen among patients with both diabetes and hypertension in the medical therapy group. The probabilistic sensitivity analysis of this model indicated that surgical therapy is favoured at willingness-to-pay thresholds above $\$ 12000$ (Figure 2).

Results of the lifetime horizon model are reported in Appendix 5. Considering health system costs, the lowest cost option was standard care; however, this resulted in the fewest QALYs. Compared with standard care, surgery had an ICER of \$14 080 per QALY, and medical therapy was more costly and less effective than surgery. In 1-way sensitivity analysis, the lifetime model was sensitive to the cost of having both diabetes and hypertension in the standard care group (Appendix 6). Comparing surgery with standard care, surgery became the dominant approach, with minimal increases in the cost of this heath state. The probabilistic sensitivity analysis indicated that, from the health care system perspective, surgical therapy was preferred at willingness-to-pay thresholds above \$23000 (Figure 2).

Using a societal perspective and a lifetime time horizon, surgery was the lowest cost option compared with medical and standard care (Appendix 5). In 1-way sensitivity analysis, when comparing surgery with standard care, the increasing cost of having no comorbidities in the surgery arm altered the results such that surgery had a positive ICER (Appendix 6). In probabilistic sensitivity analysis, surgical therapy is preferred at all willingness-to-pay values (Figure 2).

\section{Interpretation}

Using prospectively collected, real-world data, we calculated the cost and utility of surgical therapy, medical therapy and standard care for the treatment of severe obesity, from both the public health care system and societal perspectives. We have demonstrated that the perspective taken alters the results of this comparison, with surgical and medical treatment becoming more attractive from the societal perspective. This is most pronounced in the short run; as time progresses, the overarching results begin to converge and surgery emerges as the most cost-effective method across a wide range of willingness-to-pay thresholds. From the societal perspective, surgery becomes the lowest cost option over time, dominating medical therapy and standard care. Surgery also exhibits the highest level of utility gains, and therefore increases quality of life more than medical or standard therapy.

Our finding that bariatric surgery is either cost-effective or cost-saving is congruent with previous published reports. ${ }^{11,12,25-29}$ However, many previous studies do not consider the societal perspective; as obesity has effects on many facets of life, failing to take into account the breadth of this impact reduces the applicability of these studies. ${ }^{3,11,28,29}$ Moreover, many studies do not consider comparative therapies or real-world data, making our study more informative and valuable for decision-makers. ${ }^{11,12}$ Finally, application of a lifetime time horizon better reflects the long-term impact of obesity interventions, an approach often not pursued in previous studies. ${ }^{11}$

By creating a model that directly reflects prospectively collected data, and using each individual's data points in custom distributions, the 2-year model incorporates realworld heterogeneity and variability, including the costs of surgical complications. This approach reduces parameter and model uncertainty, and increases the validity of the probabilistic sensitivity analysis. For our long-term models, using real-world data and sources such as the Framingham Risk Score and the Health Quality Council of Alberta to externally validate parameter estimates, we reduced parameter uncertainty. ${ }^{30}$

Conservative assumptions of the long-term effects of surgery and the impact of untreated or ineffectively 
treated obesity likely reduced the magnitude of difference in mortality and comorbidity rates between bariatric surgery and the other treatment arms. This was supported by the 1-way sensitivity analysis; although changes in parameters rarely altered the direction of the ICER, the magnitude was often sensitive to mortality rates for different health states. Conservative assumptions likely underestimate the cost-effectiveness of bariatric surgery relative to other treatment approaches.

In general, model results were robust to parameter changes. It is noteworthy that, in every 1-way sensitivity analysis, the cost of having hypertension and diabetes in the standard care group was one of the most sensitive model parameters. Cost estimates for this parameter have a wide range, with a mean value that is notably higher than most other nondeath states, which likely contributes to its impact on ICER. From a conceptual standpoint, this emphasizes how the cost of comorbidities can affect overall costs; reduction in the prevalence of hypertension and diabetes via therapy reduces both health care and societal costs.

\section{Limitations}

We used a friction approach to calculate societal costs, as per the Canadian Agency for Drugs and Technologies in Health guideline. ${ }^{19}$ Relative to the human capital approach, this may underestimate societal costs, particularly in the standard care and medical therapy groups, as there were greater levels of disability and unemployment in those groups.

Hypertension and diabetes were chosen as health states because they have been illustrated to be drivers of cost and death. ${ }^{31,32}$ However, we omitted numerous other health states that are common among patients living with obesity, such as sleep apnea or coronary artery disease. It is logical to assume that the costs associated with other common diagnoses are included in the analysis, and exist in each treatment arm at the rate that they would coexist with hypertension or diabetes. Given the multifaceted nature of obesity, it is impractical to label each possible comorbidity, and their iterative combinations, as health states. Furthermore, the number of probability estimations would increase uncertainties in the model. ${ }^{33}$

The APPLES study was conducted before the introduction of pharmaceuticals such as liraglutide and combination naltrexone and bupropion. These are being used perioperatively and instead of surgery, and will therefore likely affect both cost and outcomes in medical and surgical groups. Future studies will be needed to understand the long-term clinical and economic impact of these technologies. ${ }^{34-36}$

This study was conducted using single centre, observational data. Although this institution uses up-to-date, multidisciplinary approaches, with outcomes comparable to those in the literature, this study does not account for variation in practice between centres, which may influence cost and outcome.

\section{Conclusion}

Bariatric surgery resulted in the greatest gains in health-related quality of life. From the publicly funded health care system perspective, surgery is cost effective. From a societal perspective, surgery becomes cost saving. These findings, using real-world data, support using surgical therapy for severe obesity, and provide a robust analysis from the societal perspective.

\section{References}

1. Padwal RS, Rueda-Clausen CF, Sharma AM, et al. Weight loss and outcomes in wait-listed, medically managed, and surgically treated patients enrolled in a population-based Bariatric program: prospective cohort study. Med Care 2014;52:208-15.

2. Rudisill C, Charlton J, Booth HP, et al. Are healthcare costs from obesity associated with body mass index, comorbidity or depression? Cohort study using electronic health records. Clin Obes 2016;6:225-31.

3. Gulliford MC, Charlton J, Booth HP, et al. Costs and outcomes of increasing access to bariatric surgery for obesity: cohort study and cost-effectiveness analysis using electronic health records. Value Health 2017;20:85-92.

4. Kitahara CM, Flint AJ, Berrington de Gonzalez A, et al. Association between class III obesity (BMI of $40-59 \mathrm{~kg} / \mathrm{m}^{2}$ ) and mortality: a pooled analysis of 20 prospective studies. PLoS Med 2014;11:e1001673.

5. Padwal RS, Majumdar SR, Klarenbach S, et al. The Alberta population-based prospective evaluation of the quality of life outcomes and economic impact of bariatric surgery (APPLES) study: background, design and rationale. BMC Health Serv Res 2010;10:284.

6. Arterburn DE, Olsen MK, Smith VA, et al. Association between bariatric surgery and long-term survival. FAMA 2015;313:62-70.

7. Bariatric surgery in Canada [spreadsheet]. Ottawa: Canadian Institute for Health Information; 2014.

8. Schauer PR, Bhatt DL, Kashyap SR. Bariatric surgery versus intensive medical therapy for diabetes. N Engl 7 Med 2014;371:682.

9. Gloy VL, Briel M, Bhatt DL, et al. Bariatric surgery versus non-surgical treatment for obesity. Br J Sports Med 2016;50:246.

10. Gloy VL, Briel M, Bhatt DL, et al. Bariatric surgery versus non-surgical treatment for obesity: a systematic review and meta-analysis of randomised controlled trials. BM7 2013;347:f5934.

11. Padwal R, Klarenbach S, Wiebe N, et al. Bariatric surgery: a systematic review of the clinical and economic evidence. 7 Gen Intern Med 2011;26:1183-94.

12. Borisenko O, Adam D, Funch-Jensen P, et al. Bariatric surgery can lead to net cost savings to health care systems: results from a comprehensive European decision analytic model. Obes Surg 2015;25:1559-68.

13. Gill RS, Majumdar SR, Rueda-Clausen CF, et al. Comparative effectiveness and safety of gastric bypass, sleeve gastrectomy and adjustable gastric banding in a population-based bariatric program: prospective cohort study. Can $\mathcal{f}$ Surg 2016;59:233-41.

14. Lester EL, Padwal R, Majumdar SR, et al. Association of preference-based health-related quality of life with weight loss in obese adults. Value Health 2017;20:694-8.

15. Gabert DL, Majumdar SR, Sharma AM, et al. Prevalence and predictors of self-reported sexual abuse in severely obese patients in a population-based bariatric program. 7 Obes 2013;2013:374050.

16. Warkentin LM, Majumdar SR, Johnson JA, et al. Weight loss required by the severely obese to achieve clinically important differences in health-related quality of life: two-year prospective cohort study. $B M C$ Med 2014;12:175.

17. Warkentin LM, Majumdar SR, Johnson JA, et al. Predictors of health-related quality of life in 500 severely obese patients. Obesity (Silver Spring) 2014; 22:1367-72.

18. Nutrition guideline: bariatric surgery for adults. Edmonton: Alberta Health Services; 2012.

19. Guidelines for the economic evaluation of health technologies: Canada. 3rd ed. Ottawa: Canadian Agency for Drugs and Technologies in Health; 2006.

20. Shaw JW, Johnson JA, Coons SJ. US valuation of the EQ-5D health states: development and testing of the D1 valuation model. Med Care 2005; 43:203-20.

21. Koopmanschap MA, Rutten FF, van Ineveld BM, et al. The friction cost method for measuring indirect costs of disease. F Health Econ 1995;14:171-89.

22. Table 18-10-0005-01: Consumer Price Index, annual average, not seasonally adjusted. Ottawa: Statistics Canada. Available: www.statcan.gc.ca/tables -tableaux/sum-som/101/cst01/econ161j-eng.htm (accessed 2018 June 20).

23. Inflation Calculator. Ottawa: Bank of Canada. Available: www.bankofcanada. $\mathrm{ca} / \mathrm{rates} / \mathrm{related} /$ inflation-calculator/ (accessed 2018 June 20).

24. Eddy DM, Hollingworth W, Caro JJ, et al.; ISPOR-SMDM Modeling Good Research Practices Task Force. Model transparency and validation: a report of the ISPOR-SMDM Modeling Good Research Practices Task Force-7. Value Health 2012;15:843-50.

25. Borisenko O, Adam D, Funch-Jensen P, et al. Response to the comment on "Bariatric surgery can lead to net cost savings to health care systems: results from a comprehensive European decision analytic model". Obes Surg 2015;25:1256-7.

26. Borisenko O, Burdukova E, Hargreaves J, et al. Cost-utility of bariatric surgery in France and Germany. Value Health 2015;18:A671.

27. Borisenko O, Burdukova E, Hargreaves J, et al. Cost-utility of bariatric surgery in Belgium, Denmark, and Italy. Value Health 2015;18:A670-1. 
28. Castilla I, Mar J, Valcárcel-Nazco C, et al. Cost-utility analysis of gastric bypass for severely obese patients in Spain. Obes Surg 2014;24:2061-8.

29. Belarbi S, Kusel J, Maruszczak M, et al. The cost-effectiveness of bariatric surgery in Germany. Value Health 2015;18:A393.

30. Echouffo-Tcheugui JB, Batty GD, Kivimäki M, et al. Risk models to predict hypertension: a systematic review. PLoS One 2013;8:e67370.

31. The cost of obesity in Alberta: summary report. Edmonton: Alberta Health Services; 2010.

32. Anis AH, Zhang W, Bansback N, et al. Obesity and overweight in Canada: an updated cost-of-illness study. Obes Rev 2010;11:31-40.

33. Roberts M, Russell LB, Paltiel AD, et al.; ISPOR-SMDM Modeling Good Research Practices Task Force. Conceptualizing a model: a report of the ISPOR-SMDM Modeling Good Research Practices Task Force-2. Value Health 2012;15:804-11.

34. Prescription medications. Edmonton: Obesity Canada, University of Alberta. Available: https://obesitycanada.ca/managing-obesity/prescription-medications/ (accessed 2021 June 21).

35. Khalil H, Ellwood L, Lord H, et al. Pharmacological treatment for obesity in adults: an umbrella review. Ann Pharmacother 2020;54:691-705.

36. Camilleri M, Acosta A. Combination therapies for obesity. Metab Syndr Relat Disord 2018;16:390-4.

Affiliations: Departments of Surgery (Lester, Birch) and Medicine (Padwal, Sharma, So, Ye, Klarenbach), University of Alberta, Edmonton, Alta.
Contributors: All of the authors contributed to the conception and design of the work. Raj Padwal, Daniel Birch, Arya Sharma and Scott Klarenbach acquired the data, which Erica Lester, Helen So and Feng Ye analyzed and interpreted. Erica Lester drafted the manuscript. All authors revised the manuscript critically for important intellectual content, gave final approval of the version to be published and agreed to be accountable for all aspects of the work.

Funding: No funding was received for this study.

Content licence: This is an Open Access article distributed in accordance with the terms of the Creative Commons Attribution (CC BY-NC-ND 4.0) licence, which permits use, distribution and reproduction in any medium, provided that the original publication is properly cited, the use is noncommercial (i.e., research or educational use), and no modifications or adaptations are made. See: https://creativecommons.org/licenses/ by-nc-nd/4.0/

Data sharing: The data used in this study are proprietary and are not available to other researchers.

Supplemental information: For reviewer comments and the original submission of this manuscript, please see www.cmajopen.ca/content/9/2/ E673/suppl/DC1. 